\title{
Manufacturing, Physical and Chemical Characterization of Fire Clay Brick Value Added with Cow Dung Ash
}

\author{
Pius Rodney Fernando*, Somasundaram Krishanth, Nilantha Bandara Rathnayake, \\ Shanilka Aruni Welarahne
}

Department of Physics, Faculty of Science, Eastern University, Chenkalady, Vanthrumoolai, Sri Lanka

Email address:

Piusrf@gmail.com (P. R. Fernando)

${ }^{*}$ Corresponding author

\section{To cite this article:}

Pius Rodney Fernando, Somasundaram Krishanth, Nilantha Bandara Rathnayake, Shanilka Aruni Welarahne. Manufacturing, Physical and Chemical Characterization of Fire Clay Brick Value Added with Cow Dung Ash. American Journal of Materials Synthesis and Processing. Vol. 4, No. 1, 2019, pp. 32-36. doi: 10.11648/j.ajmsp.20190401.14

Received: May 25, 2019; Accepted: June 24, 2019; Published: July 12, 2019

\begin{abstract}
Aim of this study was to introduce an eco-friendly, low cost and durable clay bricks with partial substitution of Cow Dung Ash (CDA). Five types of clay brick, consist CDA percentages 0, 510,15 and 20\% to the total weight of mixture, were manufactured by employing traditional method of dimension $(18.5 \times 8.5 \times 6.5) \mathrm{cm}^{3}$. The clay and CDA were well mixed with the addition of sufficient amount of water to form a good workability. Green molded bricks were allowed to dry under sunlight for two days and then fired in the traditional brick kiln. Physical properties of the burned red bricks were then tested and analyzed with Sri Lankan and British Standard Specifications. The average density, water absorption, compressive strength and flexural strength for $10 \%$ Cow Dung Ash (CDA) are $1447 \mathrm{~kg} \cdot \mathrm{m}^{-3}, 17 \%, 150 \mathrm{~kg} . \mathrm{cm}^{-2}$ and $0.82 \mathrm{~kg} . \mathrm{cm}^{-2}$ respectively. These physical properties were compared with the standard brick purely manufactured from clay. From the results, clay-CDA bricks are obviously superior to the control brick; those are available in the Eastern region markets.
\end{abstract}

Keywords: Cow Dung, Cow Dung Ash, Fired Clay Bricks, Compressive Strength, Flexural Strength, Value Addition, Water Absorption, Eco-friendly

\section{Introduction}

Clay bricks are most important building materials, because of its eco-friendly nature. Since the ancient period these bricks are manufactured locally and have been emphasized all over the world because of their eco-friendly nature and low cost. However, the efficiency of the brick is an important factor for construction. This factor has been improved by utilizing the locally available sources such as agricultural and industrial waste. To overcome this, a challenge has been taken to increase the efficiency of clay brick by adding suitable waste materials along with clay in the manufacturing process [1-16]. Therefore, considering environmental impact and the efficiency, there is a need to select an alternative material to reduce the impact of brick manufacturing on the environment as well as increase the overall performance of the brick. Many research studied shows that some admixtures increase the bond between the particles and thus increase the efficiency of the brick. Such admixtures are lime, sawdust ash, rice husk ash, ground nut shell ash, coconut shell ash, bamboo leaf ash, tobacco leaf ash, rice husks, sawdust, etc., [1-12]. Therefore, the main aim of the research was to disseminate the knowledge of admixtures among the brick making community and to build a green environment by utilizing the natural agro waste materials. This research investigated the effect of clay brick with partial addition of Cow Dung Ash (CDA) on the efficiency of the brick.

\section{Experimental Methodology}

\subsection{Materials}

\subsubsection{Brick Clay}

Clay was collected from Verpavettuvan, which is located in Batticaloa District, Eastern Province of Sri Lanka. The chemical analyses shows that the major chemical compositions of the clay are silica, alumina, and ferric oxide, 
are tabulated in Table 1. The higher silica percentage in the

clay increases the efficiency of the brick [9].

Table 1. Chemical compositions of Verpavettuvan clay.

\begin{tabular}{llllllllllll}
\hline Compounds (\%) & $\mathbf{S i O}_{2}$ & $\mathbf{F e}_{2} \mathbf{O}_{3}$ & $\mathbf{A l}_{2} \mathbf{O}_{3}$ & $\mathbf{C a O}$ & $\mathbf{M g O}$ & $\mathbf{S O}_{3}$ & $\mathbf{N a}_{2} \mathbf{O}$ & $\mathbf{K}_{2} \mathbf{O}$ & $\mathbf{T i O}_{2}$ & $\mathbf{P}_{2} \mathbf{O}_{3}$ & $\mathbf{L I O}$ \\
\hline Present study [10, 11] & 63.10 & 9.23 & 10.63 & 5.03 & 0.02 & 0.01 & 1.03 & 0.02 & - & - & 8.23 \\
Badr El-Din et al. [12] & 65.20 & 7.36 & 15.26 & 1.01 & 0.83 & 0.08 & 3.12 & 0.62 & 1.92 & 0.15 & 6.01 \\
\hline
\end{tabular}

\subsubsection{Cow Dung Ash (CDA)}

The cow dung was collected from animal science farm, Eastern University, Sri Lanka. The CDA were cleaned and allowed to sun dried. Dried CDA was well ground and mixed with the clay. The chemical compositions of cow dung was tested and tabulated in Table 2, compared with the previous studies. The $\mathrm{SiO}_{2}$ has a high binding property which enhances the efficiency of the brick.

Table 2. Chemical Compositions of Cow Dung Ash (CDA).

\begin{tabular}{|c|c|c|c|c|c|c|c|c|c|c|c|}
\hline Compounds (\%) & $\mathrm{SiO}_{2}$ & $\mathrm{Fe}_{2} \mathrm{O}_{3}$ & $\mathrm{Al}_{2} \mathrm{O}_{3}$ & $\mathrm{CaO}$ & MgO & $\mathrm{SO}_{3}$ & $\mathrm{Na}_{2} \mathrm{O}$ & $\mathrm{K}_{2} \mathrm{O}$ & $\mathrm{TiO}_{2}$ & $\mathbf{P}_{2} \mathbf{O}_{3}$ & $\mathrm{Mn}_{2} \mathrm{O}_{5}$ \\
\hline Present study & 69.50 & 3.58 & 3.98 & 12.99 & 2.25 & 1.89 & 0.42 & 2.59 & 0.47 & 1.58 & 0.75 \\
\hline Omoniyi et al. [17] & 69.95 & 2.99 & 4.27 & 12.55 & 2.22 & 1.36 & 0.57 & 2.94 & 0.33 & 1.48 & 0.63 \\
\hline
\end{tabular}

\subsection{Sample Preparation}

Five types of brick were manufactured by applying traditional method, which consist CDA of $0,5,10,15$ and $20 \%$ to the total weight of mixture. Each type has nine bricks of dimension $(18.5 \times 8.5 \times 6.5) \mathrm{cm}^{3}$ as shown in Table 3 . The clay and CDA was mixed well with the addition of sufficient water to get a suitable plasticity and a good workability (water/clay ratio 0.5 to 0.6 ). Then green raw material was applied into a wooden mould to get green bricks. These green bricks were allowed to dry under sunlight of temperature around $35^{\circ} \mathrm{C}$ for one week. Then the dried green bricks were burned in a brick kiln of burning temperature range $600^{\circ} \mathrm{C}$ to $850^{\circ} \mathrm{C}$, which is the industrial scale manufacturing process of fired clay bricks in the Eastern region of Sri Lanka. The burning process was continuously carried out for two days and allowed to cool in the environment. Finally, the properties of the fired bricks were analyzed.

Table 3. Different Batching Proportions of Raw Materials.

\begin{tabular}{lll}
\hline Brick Types & Brick Clay (wt. \%) & Cow Dung Ash (CDA) (wt. \%) \\
\hline 1 & 100 & 00 \\
2 & 95 & 05 \\
3 & 90 & 10 \\
4 & 85 & 15 \\
5 & 80 & 20 \\
\hline
\end{tabular}

\subsection{Analysis of Bricks}

Density, compressive strength, flexural strength and water absorption analyses were carried out in accordance to Sri Lankan and British Standards.

\subsubsection{Particle Size (PS) Analysis}

Particle analysis was not done, because the aim of the research was to disseminate the knowledge to the local markets and improve the self-employment of the local community.

\subsubsection{Water Absorption (WA) Analysis}

Three bricks in each type were selected to analyze the water absorption property of the fired clay bricks. The analysis was done in accordance with Sri Lankan Standard [18] 855: Part 1: 1989 and British Standard [19] BS 5628: Part 1: 2005. Initially, the dry weight of the bricks was measured. Then the bricks were immersed in the water for 24 hours and the wet weights of the bricks were measured. Water absorption property is calculated in percentage using the equation 1 , and the average value was calculated for each type.

$$
\text { Water absorption }=\frac{W_{2}-W_{1}}{W_{1}} \times 100 \%
$$

Where $W_{1}$ - weight of the dry brick and $W_{2}$ - weight of the wet brick after 24 hours.

\subsubsection{Compressive Strength (CS) Analysis}

Compressive strength analysis was performed using Universal Testing Machine available in the Department of Physics, Eastern University, Sri Lanka. The testing was performed in accordance to Sri Lankan Standard [18] 855: Part 1: 1989 and British Standard [19] BS BS 5628: Part 1: 2005 similar to ASTM D1365-05 standard. Three bricks from each type were measured and the average compressive strength was determined using equation 2 and compared with the Sri Lankan standards.

$$
C S=F_{m} / d \times l
$$

Where; $F_{\mathrm{m}}$ is the maximum force applied to just break the bricks (or force failure), $d$ is the width and $l$ is the length of the brick.

\subsubsection{Flexural Strength (FS) Analysis}

Flexural strength analysis was done in accordance to the Sri Lankan Standard [18] 855: Part 1: 1989 and British Standard [19] BS 5628: Part 1: 2005 similar to ASTM D1365-05 standard. The applied force failed and the other physical parameters of the brick were recorded to determine the flexural strength using equation 3.

$$
M R=F L / w h^{2}=3 F a / 2 w h^{2}
$$

Where $M R$ is flexural strength, $(\mathrm{kPa}), L$ is span length, 
(mm), $w$ and $h$ are width and height of the block, (mm) respectively, $a$ is distance between line of fracture and the nearest support, $(\mathrm{mm})$, and $F$ is applied force failed $(\mathrm{kN})$.

\subsubsection{Thermal Conductivity (TC) Analysis}

Thermal conductivity of the bricks was analyzed using Lee's Disc. Thermal conductivity is the ability to transfer heat through the material. It is a very important parameter to form a cooling effect inside the build. Using equation 4 , the thermal conductivity and the specific heat were determined.

$$
k=\frac{t_{1}}{\left(T_{0}-T_{1}\right)}\left[\frac{V^{2}}{S R}-\frac{k_{1}}{t_{2}}\left(T_{0}-T_{2}\right)\right] \text { and } C_{S}=\frac{E^{2}}{k \rho}
$$

Where $k$ and $k_{1}$ are thermal conductivity of the brick and the insulating disc respectively, $V$ is the voltage, $R$ is the resistance of the coil, $S$ is the surface area of the brick, $\rho$ is the density of the brick, $E$ is the thermal effusively, $t_{1}$ and $t_{2}$ are the thickness of the brick and insulating disc and $T_{0}, T_{1}$ and $T_{2}$ are the heated face temperature of brick, nonheated face temperature of brick and non-heated face temperature of insulating disc respectively.

\section{Results and Discussion}

\subsection{Density Analysis}

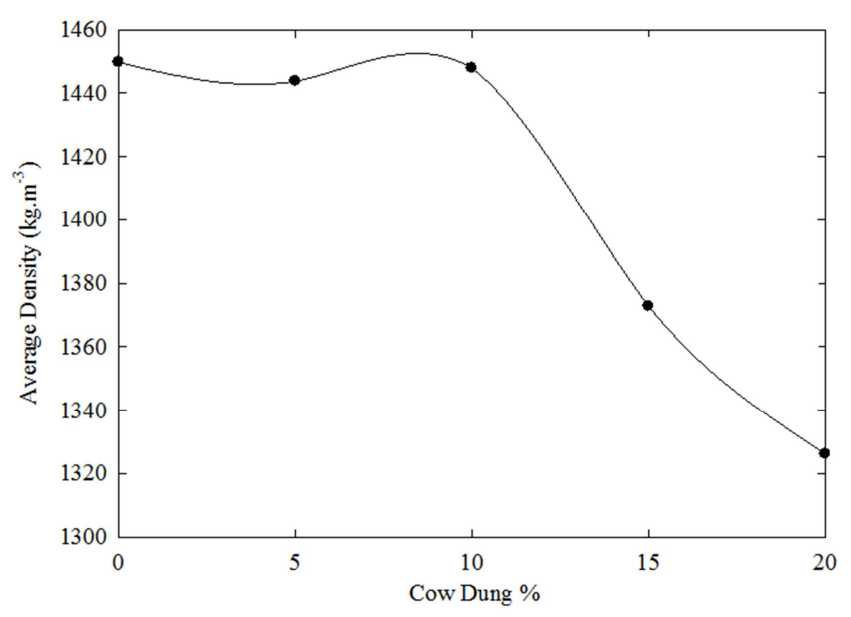

Figure 1. Average density of brick as a function of $C D A \%$.

Figure 1 shows the average density of brick slight decreases and increases up to $10 \%$ of CDA, followed that, it shows a sharp decrease. This decreasing behavior is due to addition of clay with CDA which produces large particles with larger voids with a reduction of density [7]. The maximum average density $1447 \mathrm{~kg} . \mathrm{m}^{-3}$ is obtained for brick contains $10 \%$ of CDA. Kiyohiko et.al. [20] investigation reveals that the density of the normal fired clay brick lies in the range between 1200 to $2200 \mathrm{~kg} \cdot \mathrm{m}^{-3}$. In the present study, the $10 \%$ of CDA satisfied the Kiyohiko et. al. [20] results and the brick is most suitable for construction.

\subsection{Water Absorption Analysis}

Water absorption is one of the prime indicators to analyse the quality of the brick. Figure 2 shows that water absorption of brick as a function of CDA\%. The water absorption increases sharply with increasing the CDA\%. It shows a maximum absorption $\approx 17 \%$ at $20 \% \mathrm{CDA}$. This shows that $\mathrm{CDA}$ has a major role in clay-CDA mixture. The results clearly show that all the bricks, satisfy recommended value of $12 \%$ as per the Sri Lankan Standard [18] 855: Part 1: 1989 and British Standard [19] BS 5628: Part 1: 2005which lie within the standard values. The increasing behaviour depends on presence of porosity and the effect of soft nature of the CDA particles [20].

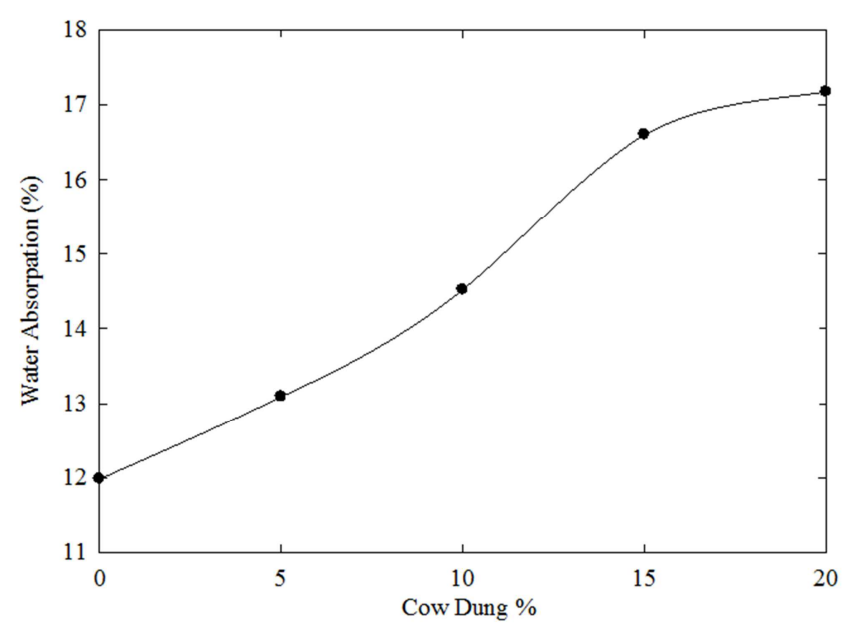

Figure 2. Average water absorption of brick as a function of $C D A \%$.

\subsection{Compressive Strength Analysis}

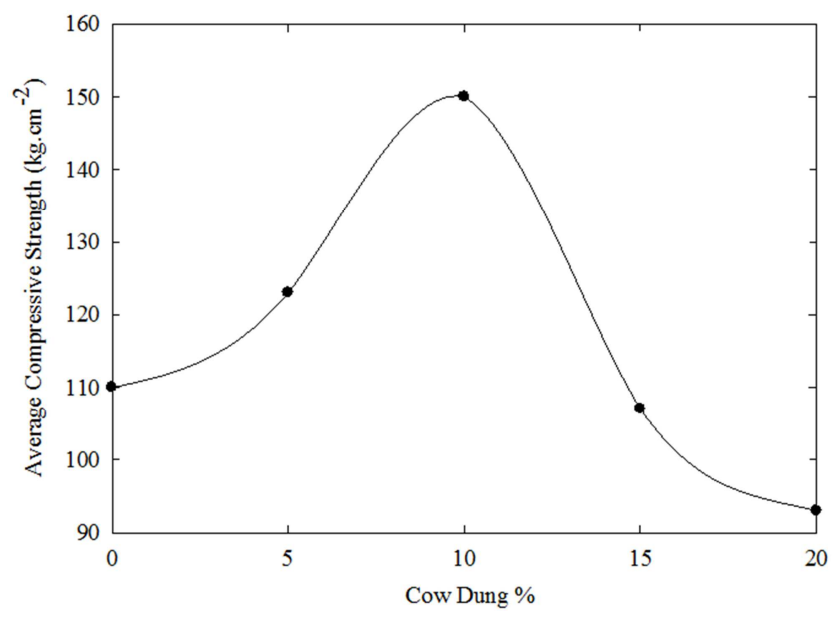

Figure 3. Average compressive strength of brick as a function of $C D A \%$.

The compressive strength analysis is shown in Figure 3. The compressive strength strongly increases from 120 $\mathrm{kg} \cdot \mathrm{cm}^{-2}\left(0 \%\right.$ CDA) to $150 \mathrm{~kg} \cdot \mathrm{cm}^{-2}(10 \% \mathrm{CDA})$ and strongly decreases to $93 \mathrm{~kg} \cdot \mathrm{cm}^{-2}(20 \%$ CDA $)$. The increase behaviour is the effect of stabilisation of the clay material due to higher percentage of $\mathrm{SiO}_{2} \mathrm{CDA}$. Therefore, $10 \% \mathrm{CDA}$ is the maximum suitable percentage to form a good bonding to increase the strength of the brick. The CDA $>10 \%$, the flabby nature of the CDA particles increase the open pores and decreases the compressive strength [21]. 


\subsection{Flexural Strength Analysis}

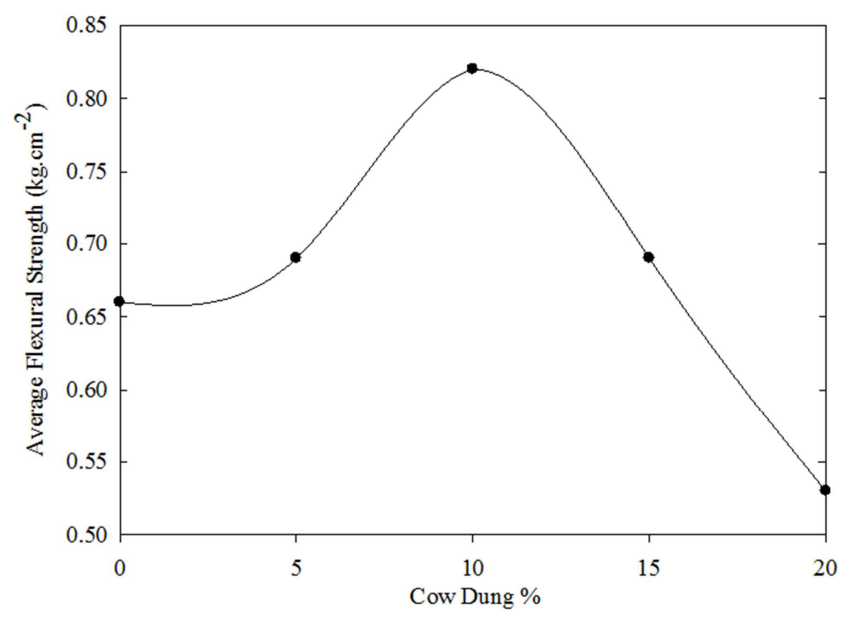

Figure 4. Average flexural strength of brick as a function of $C D A \%$.

Figure 4 shows the change in flexural strength as a function of CDA. The flexural strength increases smoothly up to 0.82 kg.cm ${ }^{-2}$ from $0.66 \mathrm{~kg} . \mathrm{cm}^{-2}$ and decreases to $0.53 \mathrm{~kg} . \mathrm{cm}^{-2}$ with increasing the CDA percentage. A maximum flexural strength $0.82 \mathrm{~kg} . \mathrm{cm}^{-2}$ is obtained for $10 \% \mathrm{CDA}$ and satisfies the required

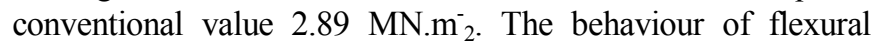
strength is similar to the behavior compressive strength.

\subsection{Thermal Conductivity and Specific Heat Analysis}

Thermal conductivity and specific heat decreases with increase of the CDA\% is shown in Figure 5. This is due increase of CDA increases the porosity of the mixture. Thus these pores support to decrease the thermal conductivity and specific heat in the mixture. The thermal conductivity and specific heat varies in the same direction as the density (see Figure 1 and Figure 5), in this fact the mixture of clay with CDA provides thermal conductivities from 0.38 to 0.16 W. $\mathrm{mK}^{-1}$ and specific heats 720 to $650 \mathrm{~J} . \mathrm{kg} . \mathrm{K}^{-1}$, lower than the thermal conductivity $0.82 \mathrm{~W} \cdot \mathrm{mK}^{-1}$ and specific heat 850 J.kg. $\mathrm{K}^{-1}$ for pure clay. This result confirms that the CDA is evidently favourable to the improvement of the thermal conductivity in the construction materials base on clay.

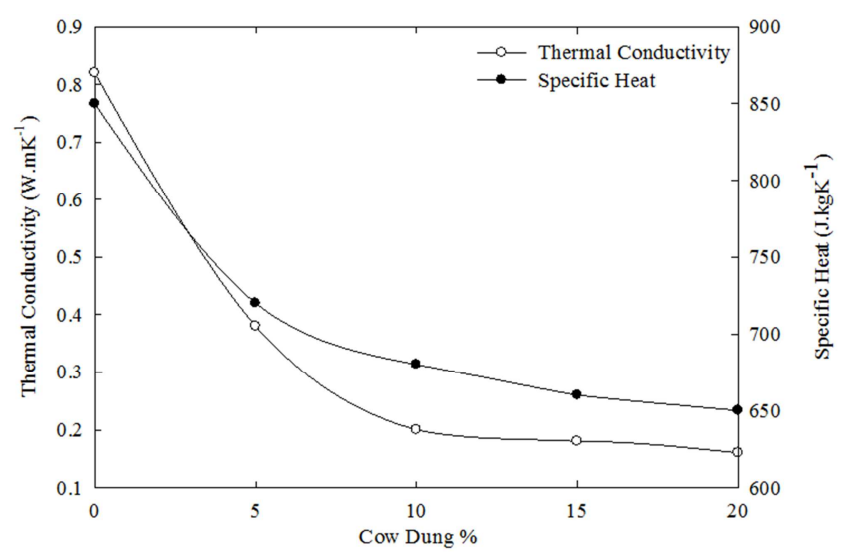

Figure 5. Thermal conductivity and Specific heat of brick as a function of $C D A \%$.

\section{Conclusions}

From various physical properties studies performed by adding different percentage of CDA, it could be concluded that partial addition of CDA improves the physical properties of the fired clay bricks within the limit of experimental error.

The results obtained from this analysis exposed that addition of $10 \% \mathrm{CDA}$ gives most favorable values in the physical properties are given as follows: The average density $1447 \mathrm{~kg} \cdot \mathrm{m}^{-3}$ was recorded and satisfy the requirements as per Sri Lankan Standard [18] 855: Part 1: 1989 and British Standard [19] BS 5628: Part 1: 2005 specifications for brick clay which stated the range in between 1200 to $2200 \mathrm{~kg} \cdot \mathrm{m}^{-3}$. According to the results, all the brick, satisfy recommended water absorption value above $12 \%$ as per the Sri Lankan Standard [18] 855: Part 1: 1989 and British Standard [19] BS 5628: Part 1: 2005 which lie within the standard values. The maximum compressive and flexural strength $150 \mathrm{~kg} . \mathrm{cm}^{-2}$ and $0.82 \mathrm{~kg} . \mathrm{cm}^{-2}$ were recorded respectively. According to the BS 5628 , compressive strength of the fired clay brick should be greater than $50.98 \mathrm{~kg} . \mathrm{cm}^{-2}$. For a single story building minimum compressive strength should be within the range 10 to $50.98 \mathrm{~kg} \cdot \mathrm{cm}^{-2}$ and recommended by the building authorities. The thermal cconductivities lay in the range 0.38 to $0.16 \mathrm{~W} \cdot \mathrm{mK}^{-1}$ and specific heats lay in the range 720 to 650 J.kg. $\mathrm{K}^{-1}$, which are lower than the values of pure clay. Therefore, $10 \% \mathrm{CDA}$ could be recommended for high strength external construction; as well as for interior wall partitions and decorations. Furthermore, this can be manufactured on site itself, low cost, semi labour skills and local economy will flourish. Not only has that by introducing the use of locally available natural agro waste materials directed to ecological structure.

\section{Acknowledgements}

The authors express their gratitude to the staff of Laboratory, Department of Physics, Maintenance Department, Eastern University, Sri Lanka and Eastern University, Sri Lanka, for providing the proper facilities to accomplish this work.

\section{References}

[1] Kute S, Deodhar S. "Effect of fly ash and temperature on properties of burnt clay bricks", Journal of Institute of Engineers, Vol. 84. Pp. 82-85, 2003.

[2] Ducman V and Kopar T. "The influence of different waste additions to clay-product mixtures", Material Technology, Vol. 416. Pp. 289-293, 2007.

[3] Hauck D, Ruppik M and Hornschemeyer S. "Influence of the raw material composition on the strength and thermal conductivity of vertically perforated clay bricks and blocks", $Z i$-Annual, annual for the brick and tile, structural ceramics and clay pipe industries, Vol. 4. Pp. 54-80, 1998. 
[4] Valenti G. L., Cioffi R., Santoro L and Ranchetti S. "Influence of chemical and physical properties of Italian fly ash on reactivity towards lime, phosphogypsum and water", Cement and Concrete Resources, Vol. 18. Pp. 91-102, 1988.

[5] Bhanumathidas N and Kalidas N. "New trends in bricks and blocks - the role of FaL-G", Indian Concrete Journal, Vol. 66. Pp. 389-392, 1992.

[6] Singh L. P. "Investigation of physical properties of bricks utilizing fly ash, lime and gypsum", Master thesis, Kanpur University, Kanpur, India, 1994.

[7] Kumar S. "Fly ash-lime-phosphogypsum cementitious binder- a new trend in bricks", Material and Structure, Vol. 33. Pp. 59-64, 2000.

[8] Kidsarin pimraksa, Mathias welhlem, Michael Kochberger and Werner Wruss." A new approach to the production of bricks made with 100\% Fly ash", 2001 International Ash Utilization Symposium. Center of Applied energy Research, University of Kentucky, Lexington, United Kingdom, 2001.

[9] De Silva P. and Crenstil K. S. 'The Effect of $\mathrm{Al}_{2} \mathrm{O}_{3}$ and $\mathrm{SiO}_{2}$ On Setting and Hardening of $\mathrm{Na}_{2} \mathrm{O}-\mathrm{Al}_{2} \mathrm{O}_{3}-\mathrm{SiO}_{2}-\mathrm{H}_{2} \mathrm{O}$ Geopolymer Systems', J. Aust. Ceram. Soc. Vol. 44. No. 1. Pp. 39-46, 2008.

[10] Fernando P. R. "Experimental Investigation of the Effect of Fired Clay Brick on Partial Replacement of Rice Husk Ash (RHA) with Brick Clay", Advances in Recycling \& Waste Management, USA, Vol. 2 (1). Pp. 120, 2017.

[11] Fernando P. R. "Mechanical and Physical Properties of Fired Clay Brick Partial Doped with Coconut Shell Ash", American Journal of Energy and Natural Resources, Vol. 6 (5). Pp. 5863, 2017.

[12] Badr El-Din Ezzat Hegazy, Hanan Ahmed Fouad and Ahmed Mohammed Hassanain. "Incorporation of water sludge, silica fume, and rice husk ash in brick making", Advances in Environmental Research, Vol. 1. Pp. 83-96, 2012.
[13] Michele Dondi, Guia Guarini, Mariarosa Raimondo, Chiara Zanelli, Daniele Dalle Fabbriche and Antonio Agostini. "Recycling the insoluble residue from titania slag dissolution (tionite) in clay bricks", Ceramic International, Vol. 36. Pp. 2461-2467, 2010.

[14] Ismail Demir. "Effect of organic residues addition on the technological properties of clay bricks", Waste Management Research, Vol. 28. Pp. 622-627, 2008.

[15] Dondi M., Guarini G., Raimondo M. and Zanelli C. "Recycling PC and TV waste glass in clay bricks and roof tiles", Waste Management, Vol. 29. Pp. 1945-1951, 2009.

[16] Kae Long Lin. "Feasibility study of using brick made from municipal solid waste incinerator fly ash slag", Journal of Hazardous Materials, Vol. 137. Pp. 1810-1816, 2006.

[17] Omoniyi, T., Duna, S. and Mohammed, A. "Compressive strength Characteristic of Cowdung ash blended cement Concrete", International Journal of Scientific \& Engineering Research, Vol. 5 (7). Pp. 770-778, 2014.

[18] Quintilio Piattoni, Enrico Quagliarini, Stefano Lenci. "Experimental analysis and modeling of the mechanical behavior of earthen bricks", Construction Building Material, Vol. 25. Pp. 2067-2075, 2011.

[19] BS 5628: PART 1: Code Of Practice For Use Of Masonry, British Standards Institute, United Kingdom, 2005.

[20] Kiyohiko I., Hyung-Sun K., Koichi K and Atsuchi, H. Influence of firing temperature on frost resistance of roofing tiles. Journal of the European ceramic Society, Vol. 24 (14), Pp. 3671-3677, 2004.

[21] Fernando P. R., Kannangara G. K., Buddhika G. P., Urushiya A. "Synthesis and Characterization of Sustainable Man-Made Low Cost Clay Bricks with Bamboo Leaf Ash". Engineering Physics, Vol. 2 (1), Pp. 15-22, 2018. 